Methods A cross-sectional exhaustive study was conducted among the 80 workers in a steel company. The recommendation of the 'analysis' level of the international standard ISO 8996 'Ergonomics of the thermal environment - Determination of metabolic rate was adopted for the evaluation of the thermal strain. The international standard ISO 7933 ' Ergonomics of the thermal environment - Analytical determination and interpretation of heat stress using calculation of the predicted heat strain' was adopted for the assessment of the thermal stress.

Thus, metabolism was evaluated based on the recording of heart rate during work withen steel workers. Moreover, physical parameters of thermal stress (air temperature, relative humidity, air velocity, globe temperature, clothing isolation, working metabolism) were assessed.

Results The equivalent metabolism was equal to $292.7 \mathrm{~W}$ $\pm 59.8 \mathrm{~W}$. Thus, workload was 'acceptable' for the majority of workers $(84.8 \%)$. Concerning the thermal stress level, $68.18 \%$ of the subjects were at risk of a long-term constraint (discomfort and risk of dehydration after several hours of exposure) and $30,3 \%$ of them faced a short term constraint (risk for Health after 30 to $120 \mathrm{~min}$ of exposure).

Discussion The present study objectively quantified the physical workload in the steel sector. For most workers, the workload was light to moderate. The long-term and short-term thermal stress objectified in this study was the source of a workstation layout and a prevention strategy.

\section{PROBE: HAZARDOUS CHEMICAL PRODUCTS REGISTER FOR OCCUPATIONAL USE IN BELGIUM}

${ }^{1} \mathrm{~S}$ Pauwels*, ${ }^{2,3} \mathrm{~A}$ Temmerman, ${ }^{4} \mathrm{~S}$ Ronsmans, ${ }^{4,5} \mathrm{~A}$ de Schryver, ${ }^{6,7} \mathrm{D}$ Rusu, ${ }^{2} \mathrm{~L}$ Braeckman, $1,4 \mathrm{~L}$ Godderis. ${ }^{1} \mathrm{~K} U$ Leuven, Department of Public Health and Primary Care, Environment and Health, Leuven, Belgium; ' $U$ Gent- Ghent University, Department of Public Health, Gent, Belgium; ${ }^{3}$ OCMW Brugge- Public Social Welfare Centre Bruges, Belgium, Service for Prevention and Protection at Work; ${ }^{4}$ IDEWE, External Service for Prevention and Protection at Work, Heverlee, Belgium; ${ }^{5}$ University of Antwerpen, Epidemiology and Social Medicine, Antwerpen, Belgium; ' ${ }^{6}$ niversity of Liège, Department of Public Health, Liège, Belgium; ${ }^{7}$ SPMT-ARISTA, External Service for Prevention and Protection at Work, Bruxelles, Belgium

\subsection{6/oemed-2018-ICOHabstracts.480}

Introduction During their job, workers are exposed to a wide variety of working conditions including chemical substances that are potentially detrimental to employees' health. Today, Belgian data on occupational exposure to dangerous chemicals are collected by Occupational Health Services (OHS) merely for the purpose of assuring the appropriate health screening. This makes these data of little use for epidemiological research and exposure surveillance on one hand and for policy development by competent authorities on the other hand.

Methods The PROBE (Hazardous chemical Products Register for Occupational use in Belgium) study is set up to investigate the exposure of Belgian workers to dangerous chemical products, including type, duration and frequency of exposure. PROBE consists of a systematic collection and analysis of occupational chemical exposure data. First, a pilot will be kicked off in a limited sample of occupational physicians, testing the feasibility of the program. A priority list of 14 chemicals was constructed for the pilot study: crystalline silica, diesel exhaust and PAHs, wood dust, formaldehyde, asbestos, isocyanates, benzene, organic solvents, lead, beryllium, powder coating, refractory ceramic fibres, welding fumes, cadmium. The data will be collected on a regular basis over a period of 5 months. Besides demographics, exposure measurements and health related data will be collected.

Results A group of 50 occupational physicians were recruited to participate in the pilot study. First results of the PROBE study will be presented at the conference.

Discussion After the pilot, a trained, motivated, and representative sample of occupational physicians from both internal and external OHS will be invited to collect data on a larger scale. The final goal of the project is to register in a comprehensive but easy way the exposure to dangerous chemicals in order to improve preventive measures, to ensure workers' health, and to develop a national surveillance policy.

\section{PROFILE OF PHYSICIANS OF THE WORK IN MINAS GERAIS GRADUATES OF THE MEDICAL RESIDENCY AND ACCREDITED COURSE OF SPECIALISATION AND THE EVALUATION OF THE COMPETENCES REQUIRED FOR THE EXERCISE OF THE MEDICINE OF THE WORK IN BRAZIL}

JR Passos* , AM Silveira, EC Dias. Hospital das Clínicas da Universidade Federal de Minas Gerais, Belo Horizonte, Brazil

\subsection{6/oemed-2018-ICOHabstracts.481}

Introduction In order to establish a more accurate diagnosis and to show a different perspective from the one shown by the study of the Medical Demography published in 2015 by the Federal Medical Council on the profile of occupational physicians in Brazil, the present study addresses the question of the profile of occupational physicians Of Minas Gerais, who graduated from the medical residency and the specialisation course, accredited by the National Association of Occupational Medicine, comparing them with the work doctors in Brazil, evaluating in each group the knowledge and skills required to practice the specialty.

Methods The study is a cross-sectional analysis using the Google Forms tool. The questionnaire consists of two blocks of variables. The first contains personal information of professionals. And the second covers the views of professionals on competencies, organised in the six areas. For each of the tasks listed, the respondents indicated the difficulty of accomplishment, the importance and the frequency with which they performed it.

Result Based on the study, it was possible to analyse the profiles of occupational physicians and to obtain a diagnosis of professional competencies, ie to identify the gap between the competencies needed to achieve the strategic objectives and the internal competences available in the training courses.

Discussion The study shows in a practical and objective way the profile and the competences of working doctors in Brazil and feeds the discussion in the light of evidence, contributing to the decision making based on medical training, allowing a transparent discussion of the variants of the specialty, Roots of some problems and inequalities shown in the training of the occupational physician. So will be able to prioritise and encourage investments in professional training and valorization, directing teaching to improve performance aimed at providing more effective responses to the working class. 